\title{
ESTÁGIO SUPERVISIONADO E OS DESAFIOS DA RELAÇÃO ENTRE TEORIA E PRÁTICA
}

\author{
LíLIAN BRANDÃo BANDEIRA \\ Universidade Estadual de Goiás (UEG), Goiânia, Goiás, Brasil \\ SílVIa Rosa da Silva Zanolla \\ SANDRA ValérIA LIMONTA Rosa \\ Universidade Federal de Goiás (UFG), Goiânia, Goiás, Brasil
}

\begin{abstract}
Resumo: As concepções formativas que subsidiam teoricamente o Estágio Supervisionado Curricular Obrigatório das licenciaturas de Educação Física têm constituído um polêmico campo de debate, sobretudo quando remetem à discussão da relação entre teoria e prática. Tendo como base a Teoria Crítica da Escola de Frankfurt, este artigo analisa o modo como a relação entre teoria e prática é discutida nas produções científicas da pós-graduação stricto sensuque tematizam o estágio. A crítica imanente e os princípios da dialética negativa de Theodor Adorno embasaram a análise dos dados e possibilitaram a compreensão das contradições existentes nas propostas conciliadoras entre teoria e prática, que prometem resolver os problemas da formação de professores e da parceria entre universidade e escola, sob o invólucro da criticidade.
\end{abstract}

Palavras-Chave: Formação de Professores. Estágio Supervisionado Curricular Obrigatório. Teoria. Prática.

\section{INTRODUÇÃO}

Este artigo tem como centro o debate sobre formação de professores a partir de reflexões feitas no Estágio Supervisionado Curricular Obrigatório dos cursos de licenciatura em Educação Física. Os dados empíricos originaram-se da produção científica da pós-graduação stricto sensu e foram coletados no âmbito de uma pesquisa de doutorado. O corpus de análise foi composto por produções defendidas entre 2002 e 2015, que possuíam como objeto de pesquisa o Estágio Supervisionado Curricular Obrigatório na formação de professores de Educação Física, na modalidade presencial.

Observa-se que, ao compor a estrutura curricular das licenciaturas, os estágios supervisionados têm, tradicionalmente, se caracterizado como um tempo e um espaço pedagógico destinados à prática. Trata-se de espaços onde os professores em formação 
realizam as intervenções pedagógicas e estabelecem um contato direto com a realidade escolar e com os sujeitos educados nessas instituições. Na dinâmica curricular dos cursos de licenciatura, os estágios objetivam articular ensino, pesquisa e extensão. Eles expressam, com evidência, a relação entre teoria e prática e entre a formação universitária e o mundo do trabalho.

Diante dessas peculiaridades no âmbito da formação de professores, os estágios supervisionados das licenciaturas em Educação Física apresentam as contradições inerentes à relação entre teoria e prática e entre universidade e escola. Nesse sentido, este artigo objetiva provocar reflexões sobre concepções formativas críticas e o desejo de resolver os problemas da realidade.

Os estudos realizados nesta pesquisa revelaram que as referências teóricas a respeito da formação de professores, acompanhadas também pelo discurso das políticas educacionais, demonstram exacerbada preocupação com a relação entre teoria e prática - como um problema a ser resolvido de forma imediata a partir dos saberes da experiência prática.

\section{ELEMENTOS CONSTITUTIVOS DAS REFLEXÕES SOBRE TEORIA E PRÁTICA APRESENTADAS NO CORPUS}

Um dos grandes desafios da formação de professores na contemporaneidade é o enfrentamento da clássica relação entre teoria e prática. Trata-se de uma questão que perpassa toda a proposta formativa dos currículos das licenciaturas, tanto em relação à formação inicial quanto em relação à formação continuada. As orientações teóricas, políticas e epistemológicas das propostas formativas elaboram diversas formas de conceber a relação entre teoria e prática, mas é principalmente no estágio supervisionado que as concepções dessas proposições formativas evidenciam suas contradições e incoerências conceituais.

A produção científica da pós-graduação stricto sensu, objeto empírico da pesquisa que subsidiou as reflexões deste texto, expressa dados representativos dessa elaboração conceitual da relação entre teoria e prática e revela concepções teóricas que se mostram eclipsadas por um discurso sedutor de inovação e resolução de problemas da prática docente, que é marcada pela exploração e pela alienação. A relação contraditória entre teoria e prática se expressa através do debate que envolve ensino e pesquisa, reflexão e ação e a clássica relação entre universidade e escola. Muitas vezes essas relações sintetizam-se no conceito de práxis. O universo do estágio supervisionado curricular obrigatório, debatido nas teses e dissertações analisadas, evidencia essas três relações à luz de referenciais hegemônicos da epistemologia da prática. Apenas três produções realizaram a análise dessas dimensões da teoria e da prática a partir do materialismo histórico-dialético marxiano.

Os anseios presentes nas concepções fundamentadas na epistemologia da prática e na concepção do materialismo histórico-dialético marxiano, do modo como foram tratados nas teses e dissertações analisadas, revelaram um objetivo comum de se 
debater a relação entre teoria e prática, entre universidade e escola e entre ensino (estágio) e pesquisa através da categoria práxis.

As reflexões desenvolvidas à luz da Teoria Crítica da Escola de Frankfurt propõem a desconstrução de elementos mitológicos e fetichizados da categoria práxis, que, pelos anseios e angústias de seus pesquisadores, recai frequentemente no engodo da resolução e da superação dos problemas da prática e da conciliação entre sujeito e objeto. Para Adorno (2009, p. 19), "o desencantamento do conceito é o antídoto da filosofia. Ele impede o seu supercrescimento: ele impede que ela se absolutize".

É nesse sentido que a crítica imanente contribui para a análise do real e se constitui um modo radical de compreensão da realidade e dos conceitos explicativos que Ihe são atribuídos (ADORNO, 2009). É importante que se explicitem as contradições sem absolutizar e dotar os conceitos de fetiches idealistas, mesmo que isso se dê em nome da criticidade e da reflexão. A positividade ${ }^{1}$ do pensamento torna-o heterônomo e a razão torna-se objeto de dominação, legitimando-se em irracionalidade e regressão.

Ao expor os elementos constitutivos das pesquisas, foi possível compreender as concepções de estágio e de formação de professores que norteiam a discussão teórica das teses/dissertações. Imbricada nessas concepções, nota-se também a relação entre teoria e prática e como ela se cristaliza em todo o processo formativo por meio do estágio supervisionado na formação de professores de Educação Física.

Outro aspecto importante dessas produções, que tematizaram o estágio supervisionado na formação de professores de Educação Física, refere-se à ênfase no papel da reflexão como mediadora da relação entre teoria e prática e da resolução de problemas concernentes ao cotidiano escolar. Nas produções de um modo geral, há descrições de experiências bem-sucedidas nos momentos do estágio supervisionado curricular obrigatório. Em uma das teses, descreve-se o êxito da proposta de estágio implementada de acordo com a formação reflexiva acerca dos problemas e das condições materiais de trabalho. Essa proposta, segundo Scherer (2008), foi efetivada por meio do desenvolvimento da criticidade dos estagiários em relação à escola e ao ensino da Educação Física. Durante a efetivação da proposta de estágio, Scherer (2008) chamou atenção para a necessidade de não negligenciar a teoria em detrimento das experiências do cotidiano. Para ele, é imprescindível que a formação inicial parta da prática na escola e contribua para a formação dos estagiários e dos professores colaboradores. Os saberes da experiência devem ser valorizados (e não somente os saberes científicos) e os cursos de formação inicial devem ampliar a reflexão sobre a realidade na e da escola (SCHERER, 2008).

Ao prosseguir com a fundamentação na perspectiva de Tardif, Scherer (2008) remeteu-se a Borges (1998), Caldeira (2001) e Terra (2003) para reafirmar essa concepção de formação docente. Esses autores consideraram que os conhecimentos construídos pelos professores estão ligados à prática, à reflexão e à experimentação cotidiana. A tese de Benites (2012) e a dissertação de Mazzocato (2014) também demonstraram influências significativas de Maurice Tardif (2002) e Cecília Borges (2000; 2008; 2011), especialmente através das categorias dos saberes docentes e da identidade profissional, em que se destaca a importância dos saberes da experiência no desenvolvimento do trabalho do professor colaborador do estágio supervisionado. Nessas produções, a proposição do trabalho colaborativo entre escola e universidade, tendo por base a 
valorização dos saberes da prática pertencentes aos professores colaboradores, foi também observada.

Outras produções, em nível de mestrado, também se remeteram a Maurice Tardif para defender a prática no processo formativo dos estágios supervisionados e estes enquanto espaços de produção de saberes inovadores. Na discussão sobre teoria e prática e o lugar que essas instâncias devem ocupar no processo formativo dos professores, o ecletismo de correntes teóricas apresentou-se recorrente nas análises. Apenas três produções, duas de mestrado e uma de doutorado, não expressavam essa incoerência conceitual e epistemológica. Por exemplo, a tese de Rodrigues (2014) que manteve coerência entre os autores citados para a análise de seu objeto de pesquisa e seus respectivos enraizamentos epistemológicos e políticos.

No entanto, ao expor questionamentos que subsidiavam sua problemática de pesquisa, Rodrigues (2014) trouxe a polarização da formação em duas perspectivas antagônicas: formação omnilateral (formação ampla que atende às várias dimensões da humanidade) e formação unilateral (fragmentada e pautada pela divisão social do trabalho). O modo como a autora expôs as críticas à formação unilateral e os argumentos de defesa da formação omnilateral podem ser compreendidos a partir da crítica adorniana aos discursos de polarização entre capitalismo tardio e sociedade industrial e entre forças produtivas e relações de produção. As polarizações tendem, segundo Adorno (1994), a interpretações equivocadas da realidade, à fetichização dos conceitos e à extinção da dialética. De acordo com Adorno (1994, p. 71), "[...] contrastar simplesmente entre si forças produtivas e relações de produções de um modo polarizado, não ficaria nada bem para uma teoria dialética".

Apesar de polarizações extremas e que, em alguns momentos, desconsideram o movimento da dialética ${ }^{2}$, as questões postas por Rodrigues (2014) suscitaram reflexões sobre a pertinência do estágio e do currículo de formação de professores, como campos capazes de abranger essa totalidade histórica, e expressaram as contradições do sistema capitalista.

Já a práxis configura-se como uma outra categoria discutida nas produções científicas, sendo passível de análise em relação às concepções de formação de professores e de estágio supervisionado. A categoria práxis é de extrema relevância para se pensar o estágio supervisionado na universidade e a relação entre teoria e prática no processo formativo de professores. Ela é utilizada para elucidar discussões que, comumente, contradizem os fundamentos epistemológicos da sua própria constituição. Na tese de Aroeira (2009), por exemplo, a categoria práxis foi incorporada à discussão sobre estágio e formação de professores, que se fundamentou, do ponto de vista filosófico, político e ideológico, na concepção da epistemologia da prática e do professor reflexivo. Isso mostra uma contradição em relação ao uso de categorias analíticas que possuem enraizamentos teóricos e epistemológicos no pragmatismo e que sinalizam, portanto, uma práxis utilitária e pragmática voltada para a transformação imediata a partir da resolução de problemas do cotidiano. Segundo a autora,

a importância dessa proposta de estudo está em questionar a potencialidade do estágio como oportunidade de colaborar para a 
BANDEIRA, L. B.; ZANOLLA, S. R. da S.; ROSA, S. V. L.

construção de um futuro professor que fortaleça sua identidade profissional por meio da reflexão da práxis docente, e que, portanto, possa desenvolver a análise crítica das práticas e a ressignificação das teorias a partir dos conhecimentos da prática. (AROEIRA, 2009, p. 27).

Como o ponto de partida são os conhecimentos da prática, a ressignificação das teorias terá a prática como ponto de partida. A práxis é vista, pois, como um modo de possibilitar a construção da identidade profissional docente, fortalecida pela reflexão sobre a práxis. Então, a reflexão utilizada como estratégia metodológica pode contribuir para a construção de saberes pedagógicos e para a própria atividade docente exercida pelos estagiários nas escolas públicas, tendo o estágio uma perspectiva colaborativa e dialética (AROEIRA, 2009).

A práxis, para Adorno (1995), está ligada às reflexões de suas relações com a teoria, uma vez que esta tem potencial transformador. A partir dos princípios da dialética negativa, a práxis, na perspectiva adorniana, sintetiza a crítica imanente, a negatividade dos conceitos e a tensão permanente, expondo as contradições da relação entre teoria e prática e a luta contra o dogmatismo estéril, que tem sido adotado por aqueles que buscam resolução imediata dos problemas da prática e desconsideram a estrutura da sociedade capitalista, contraditória e totalitária em sua gênese.

A análise da situação não se esgota na adaptação a esta. Enquanto reflete sobre ela, põe em relevo momentos que podem conduzir para além das coações, da situação. Isto assume incalculável relevância para a relação entre teoria e práxis. Por sua diferença com relação a esta, enquanto ação imediata ligada à situação e, portanto, por sua autonomização, a teoria converte-se em força produtiva prática, transformadora. Sempre que alcança algo importante, o pensamento produz um impulso prático, mesmo que oculto a ele. Só pensa quem não se limita a aceitar passivamente o desde sempre dado. (ADORNO, 1995, p. 210).

Adorno (1995) traz importantes reflexões acerca da relação entre teoria e práxis, permitindo o estabelecimento de relações com o atual contexto de semiformação cultural e de recuo da teoria no processo de formação de professores.

A assertiva de que a reflexão sobre a práxis docente fortalece a identidade do professor é questionável do ponto de vista da necessidade de coerência com a materialidade histórica atual, tomando-se como base as contribuições teóricas das categorias marxianas e, sobretudo, frankfurtianas. A análise sobre formação de professores deve se articular ao trabalho produzido sob os princípios (de)formativos do modo de produção capitalista. Para isso, é fundamental compreender o processo constitutivo das licenciaturas como parte fundamental do projeto estratégico de empobrecimento formativo dos professores e da escola. Diante desse contexto, será que a idealização da categoria práxis não tem se transformado em ideologia, contrariando a gênese marxista de sua intencionalidade? 


\begin{abstract}
Se teoria e práxis não são nem imediatamente o mesmo, nem absolutamente distintas, então sua relação é de descontinuidade. Não há uma senda contínua que conduza da práxis à teoria, isso o que se quer dizer por momento espontâneo nas considerações que seguem. Mas a teoria pertence ao contexto geral da sociedade e é, ao mesmo tempo, autônoma. Apesar disso, nem a práxis transcorre independente da teoria, nem esta é independente daquela. Se a práxis fosse o critério da teoria, converter-se-ia, por amor "thema probandum", no embuste denunciado por Marx e, por causa disso, não poderia alcançar o que pretende; se a práxis se regesse simplesmente pelas indicações da teoria, endurecer-se-ia doutrinariamente e, além disso, falsearia a teoria. (ADORNO, 1995, p. 227).
\end{abstract}

As análises adornianas sobre a práxis permitem a compreensão das contradições que esta categoria apresenta, sobretudo em suas múltiplas apropriações no universo acadêmico. Essa categoria tem sido discutida a partir de vários referenciais teóricos que, frequentemente, recorrem à sua origem marxista, mas desconsideram seu projeto político e revolucionário de sociedade. Adorno (1995, p. 207) alerta para que o fetiche da práxis não se constitua uma barricada contra a sua finalidade. Segundo ele,

esta é uma dialética desesperada: do fascínio que a práxis impõe aos homens não é possível escapar senão através da práxis, ela porém, ao mesmo tempo, - apática, estreita, carente de espírito contribui enquanto tal para reforçar esse fascínio. A mais recente aversão à teoria, que é a sua medula, faz disso um programa. Mas o fim prático, que inclui a liberação de toda obtuosidade, não é indiferente aos meios que pretendem alcançá-lo; de outra maneira, a dialética degenera em jesuitismo vulgar. (ADORNO, 1995, p. 207).

A práxis tem sido uma categoria bastante apropriada e discutida nas produções científicas sobre estágio supervisionado e, na maioria delas, aparece para resolver o clássico problema da divisão social do trabalho e para conciliar ação e reflexão.

As propostas de estágio supervisionado, em suas interfaces com a formação de professores na universidade, têm buscado conciliar e resolver a questão do trabalho e da identidade docente na escola. No entanto, é preciso cautela com as análises mecanicistas que não respeitam a origem e a contextualização política e ideológica dos conceitos, e que articulam propostas pedagógicas e formativas para projetos de sociedade antagônicos. As questões ideológicas encontram-se veladas pela realidade opaca, marcada pela divisão social do trabalho, pela alienação e pelos constructos teóricos que leem essa realidade.

TEORIA E PRÁTICA NO ESTÁGIO SUPERVISIONADO: CONCILIAÇÃO, UNIFICAÇÃO, ARTICULAÇÃO, ASSOCIAÇÃO OU SUPERAÇÃO DA DICOTOMIA? 
A discussão acerca da relação entre teoria e prática perpassa a totalidade das produções científicas analisadas e constitui preocupações constantes nos processos formativos de professores. Desse modo, foi perceptível a elaboração teórica, política e epistemológica de possíveis "fórmulas" para sanar os problemas oriundos da realidade concreta e contraditória em que se insere a formação docente.

Nas produções analisadas, foram encontradas concepções diferentes e, numa perspectiva contra-hegemônica, apenas as dissertações de Rodrigues (2007) e Alves (2010) e a tese de Rodrigues (2014) defendiam a unidade entre teoria e prática subsidiada por categorias do materialismo histórico-dialético. As demais produções discutiram a relação entre teoria e prática a partir de concepções críticas, porém, com outros referenciais teóricos e epistemológicos.

Para Kronbauer (2013), o estágio foi responsável pela unificação entre teoria e prática. E Aroeira (2009, p. 29) destaca a importância da vinculação entre teoria e prática para a promoção de "uma reflexão crítica e colaborativa sobre as ações e os problemas relacionados às práticas pedagógicas". Em outra passagem, Aroeira (2009), enfatiza o papel da reflexão como estratégia para superar a disputa entre teoria e prática.

\begin{abstract}
Evidencia-se o papel e a potencialidade da reflexão como estratégia formativa num processo de Estágio Supervisionado que busca superar a disputa entre teoria e prática, constituindo-se como prática dialética. Parte do pressuposto de que, quando o estágio é fundado na práxis, assume importante contribuição na produção de saberes por futuros professores, referenciando a reflexão como meio de redimensionar e ressignificar a prática. (AROEIRA, 2009, p. 49).
\end{abstract}

Contudo, é válido destacar que, de acordo com a Teoria Crítica da Escola de Frankfurt, a relação entre teoria e prática não é de continuidade, de identificação e nem de simples articulação ou vinculação. A relação entre teoria e prática é de contradição, perpassada por um constante estado de tensão, visto que a teoria está ligada à prática e, ao mesmo tempo, é autônoma a ela.

\footnotetext{
O dogma da unidade entre teoria e práxis é, em oposição à doutrina a que se reporta, adialético: ele capta simples identidade ali onde só a contradição tem chance frutífera. Embora a teoria não possa ser arrancada do conjunto do processo social, também tem independência dentro do mesmo; ela não é somente meio do todo, mas também momento; não fosse assim, não seria capaz de resistir ao fascínio do todo. (ADORNO, 1995, p. 227).
}

Essa perspectiva de articular teoria e prática como pertencentes à mesma natureza identitária ${ }^{3}$, ou ainda trazer a categoria práxis como redenção da relação e/ou dicotomia entre teoria e prática, foi constante nas produções sobre estágio supervisionado e formação de professores de Educação Física. "Em pontos nodais do desenvolvimento, de ruptura qualitativa, podem reflexão e ação detonar-se mutuamente; mas nem mesmo então são ambas a mesma coisa" (ADORNO, 1995, p. 
Estágio supervisionado e os desafios da relação...

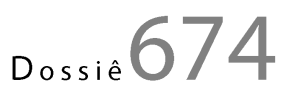

210). Para Adorno e Horkheimer (1985), a relação entre teoria e prática é de contradição, pautada pelos pressupostos da dialética negativa.

\begin{abstract}
A teoria crítica da sociedade não possui conceito algum que possa cobrir a lacuna entre o presente e o seu futuro; não oferecendo promessa alguma e não oferecendo êxito algum, permanece negativa. Assim, ela deseja permanecer leal àqueles que, sem esperança, deram e dão sua vida à Grande Recusa. No início da era fascista, Walter Benjamin escreveu: Nur um der Hoffnungslosen willen ist die Hoffnung gegeben. Somente em nome dos desesperançados nos é dada esperança. (MARCUSE, 1982, p. 235; grifo do autor).
\end{abstract}

Nesse sentido, as análises dos intelectuais da Escola de Frankfurt podem contribuir para a reflexão sobre a radicalidade dos discursos que embasam concepções hegemônicas de estágio e formação de professores de Educação Física, e seus nexos com a relação entre teoria e prática. Os estágios supervisionados, mesmo que orientados pela práxis, não podem se constituir como panaceia para os problemas concernentes à relação entre teoria e prática, universidade e escola, ensino e pesquisa, porque se orientam a partir da lógica da estrutura social capitalista e totalitária. É a partir desse contexto totalitário de dominação e de predominância dos aspectos unidimensionais do homem que Marcuse (1982) ressalta a importância de se manter a contradição e a negação como princípios de análise da realidade social.

Não obstante, existem todos os fatos que validam a teoria crítica dessa sociedade e do seu fatal desenvolvimento: a crescente irracionalidade do todo; desperdício e restrição da produtividade; necessidade de expansão agressiva; ameaça constante de guerra; exploração intensificada; desumanização. $E$ todos indicam a alternativa histórica: a utilização planejada dos recursos para a satisfação de necessidades vitais com um mínimo de labuta, a transformação das horas de lazer em tempo livre, a pacificação da luta pela existência. Mas os fatos e as alternativas existem como fragmentos que não se casam, ou como um mundo de objetos mudos sem um sujeito, sem a prática que moveria esses objetos na nova direção. A teoria dialética não é refutada, mas não pode oferecer remédio. Não pode ser positiva. (MARCUSE, 1982, p. 231232).

Outro aspecto das propostas conciliadoras entre teoria e prática refere-se à superação da dicotomia existente entre essas duas dimensões da formação de professores, que potencialmente expressam suas contradições nos estágios supervisionados. Aroeira (2009) relatou que sua proposta de estágio, baseada na epistemologia da práxis, pôde contribuir para a superação da separação entre teoria e prática. A epistemologia da práxis tornou-se uma concepção de estágio e formação de professores adotada nas dissertações de Aroeira (2009) e Sousa (2012), em 
contraposição à epistemologia da prática profissional. Trata-se de uma concepção que adota a categoria práxis, mas como constructo asséptico, pois a dissocia da essência transformadora da realidade como totalidade histórica e contraditória. A epistemologia da práxis também consiste, conforme discussão das autoras das dissertações supracitadas, numa concepção fetichizada, porque delega à práxis um caráter transformador dissociado da discussão do trabalho no modo de produção capitalista, além do caráter superador das dicotomias entre teoria e prática. É uma concepção que expressa o que Adorno (1994) denominou de "estéril dogmatismo".

Em uma das teses analisadas, a concepção de prática está articulada à concepção de ensino reflexivo, do professor reflexivo e da valorização dos saberes docentes. Sob a influência de Donald Schön (1995 apud Ramos 2002), o autor afirmou que os problemas oriundos da prática docente não podem ser vistos como meramente instrumentais e que, por isso, "exigem respostas únicas, nem sempre adquiridas e/ou aprendidas através do conhecimento técnico, na Universidade" (RAMOS, 2002, p. 45-46). Esse autor, utilizando também do embasamento teórico de Maurice Tardif, afirmou que "é a valorização da prática enquanto produtora de seus próprios saberes, e não um espaço de aplicação dos saberes provenientes da teoria" (TARDIF, 2000 apud RAMOS, 2002, p. 87).

Esse é um ponto de vista recorrente nas reflexões das produções analisadas e sinalizam, a partir das especificidades de suas pesquisas empíricas, a necessidade de valorização dos saberes produzidos na prática dos professores colaboradores dos estágios (BENITES, 2012; MAZZOCATO, 2014), e a necessidade da construção e valorização da identidade docente (BEZERRA, 2012; SOUSA, 2012; ZANCAN, 2012; TÉO, 2013). Essa valorização da construção da identidade docente, que negligencia o debate sobre as relações produtivas do trabalho no modo de produção capitalista, traz a conciliação entre teoria e prática como possibilitadora da construção da identidade docente, recaindo em contradições que ocultam os mecanismos de dominação e alienação dos professores.

Marcuse (1982, p. 27), ao trazer uma discussão sobre as novas formas de controle, faz o seguinte questionamento: "Como podem as pessoas que tenham sido objeto de dominação eficaz e produtiva criar elas próprias as condições de liberdade?" Essa questão revela o avançado estado de heteronomia que a humanidade se encontra e traz elementos para se problematizar o atual contexto da formação de professores.

Como as teorias do professor reflexivo e da epistemologia da prática, predominantes no debate sobre formação de professores, expressam esse anseio de resolução dos problemas da prática pedagógica e do cotidiano escolar e prometem liberdade, autonomia e emancipação aos sujeitos imersos num contexto alienante? Assim, Marcuse (1982) contribui com reflexões importantes para a problematização de teorias formativas que se propõem à construção da autonomia e da emancipação humana, mas, que, contraditoriamente, estão interligadas à manutenção da alienação do trabalho docente e à não ruptura com o processo produtivo capitalista.

As noções de estágio e formação de professores presentes nas produções analisadas também expressam concepções de teoria, de prática e do modo como essas dimensões formativas se relacionam com a produção de conhecimento sobre a temática desta investigação. A epistemologia da prática, como concepção hegemônica de formação de professores e de estágio supervisionado, a concepção da epistemologia da 
práxis e a concepção baseada no materialismo histórico-dialético adotam a práxis como categoria propositiva para o debate sobre a relação entre teoria e prática.

Diferente das produções científicas da pós-graduação stricto sensu sobre estágio e formação de professores de Educação Física, as reflexões deste artigo orientam-se a pelos princípios da Teoria Crítica da Escola de Frankfurt e, portanto, adotam a perspectiva da contradição entre teoria e prática e da práxis apartada do fetichismo e de um estéril dogmatismo (ADORNO, 1994).

A aversão à teoria também é um elemento da práxis adotado nas produções analisadas, sob o invólucro da criticidade e do pensamento reflexivo. A práxis esvaziada de teoria e que, declaradamente, defende a supremacia dos saberes da experiência torna-se frágil e não contribui para a luta contra a barbárie. Segundo Adorno (1995, p. 211), "práxis sem teoria, abaixo do nível mais avançado do conhecimento, tem que fracassar e, segundo seu conceito, a práxis deveria realizá-lo. Falsa práxis não é práxis".

Assim, para se respaldar na Teoria da Escola de Frankfurt, este estudo buscou coerência com os princípios da dialética negativa adorniana, sobretudo através da crítica imanente e da busca pelo entendimento dos fundamentos teóricos norteadores das propostas de formação de professores, segundo o entendimento de suas contradições internas. Buscou-se ainda o entendimento das concepções formativas com base em elementos, contraditoriamente, negados por elas, a partir da formulação de seus objetivos e finalidades.

Com isso, a máxima frankfurtiana de não se levar pelo engodo travestido de inovação, promessa de felicidade e emancipação também pode ser relacionada com as contradições expressas pelas concepções do professor reflexivo e da epistemologia da prática, pois, ao priorizarem os saberes da experiência e do cotidiano e o conhecimento subsumido à utilidade imediata, jamais cumprirão a promessa de emancipação e de formação humana. O discurso democrático das propostas formativas, desde a sua gênese, não tem cumprido a promessa de proporcionar a autonomia, a emancipação e a resolução dos problemas da prática docente.

De forma análoga à Odisseia de Homero, Adorno e Horkheimer (1985) trazem uma questão importante para se pensar as promessas semiformativas no âmbito da educação, que tem amplo respaldo nas propostas pedagógicas de formação de professores na universidade. Muitas propostas de formação de professores têm se identificado como inovadoras e capazes de resolver o "problema" da relação entre teoria e prática, entre escola e universidade e entre formação e atuação profissional. No entanto, ao permanecerem subsidiadas pelos princípios políticos e epistemológicos do pragmatismo, essas propostas demonstraram várias contradições que puderam ser percebidas com a análise das categorias da dialética negativa.

Ao se priorizar os meios, através da instrumentalidade da razão, os fins ligados ao sentido emancipatório da humanidade são comprometidos, pois os parâmetros do pragmatismo e do utilitarismo são predominantes nas interfaces existentes entre formação e atuação profissional que incidem de modo significativo nos estágios supervisionados dos currículos das licenciaturas. Esse processo de instrumentalização da razão e de subsunção dos fins aos meios desvincula a teoria da práxis, menosprezando a 
teoria em prol da valorização da prática heterônoma. Adorno e Horkheimer $(1985$, p. 11) afirmam que:

O que nos propuséramos era, de fato, nada menos do que descobrir porque a humanidade, em vez de entrar em um estado verdadeiramente humano, está se afundando em uma nova espécie de barbárie. [...] Embora tivéssemos observado há muitos anos que, na atividade científica moderna, o preço das grandes invenções é a ruína progressiva da cultura teórica, acreditávamos de qualquer modo que podíamos nos dedicar a ela na medida em que fosse possível limitar nosso desempenho à crítica ou ao desenvolvimento de temáticas especializadas.

O processo de recuo e recusa da teoria, aliado ao que Adorno e Horkheimer (1985) chamam de ruína da cultura teórica, expressa o tipo de racionalidade que fundamenta o positivismo e o pragmatismo, definido por Horkheimer (2002) como razão instrumental. "A formalização da razão é a mera expressão intelectual do modo de produção maquinal" (ADORNO; HORKHEIMER, 1985, p. 100). A razão instrumental tem seu advento com a consolidação da Modernidade e da ciência positivista, que concebe teoria e prática, sujeito e objeto como dimensões separadas.

\section{CONSIDERAÇÕES FINAIS}

A perspectiva adotada neste estudo considera teoria e prática como instâncias contraditórias, assim como analisa o modo apartado como essas dimensões formativas têm sido discutidas. Dimensões estas que se expressam na produção científica da pósgraduação stricto sensu a respeito do estágio e da formação de professores de Educação Física. Quando Adorno (1995, p. 206) se refere às formas mais antigas de "separação entre trabalho físico e mental" como gênese do processo de separação entre teoria e prática, o autor aponta que esse é um momento emblemático da origem desse processo que pode estar situado na pré-história e que, portanto, antecede a modernidade.

\footnotetext{
O que os homens querem aprender da natureza é como empregá-la para dominar completamente a ela e aos homens. Nada mais importa. Sem a menor consideração consigo mesmo, o esclarecimento eliminou com seu cautério, o último resto de sua própria autoconsciência. Só o pensamento que se faz violência a si mesmo é suficientemente duro para destruir os mitos. (ADORNO; HORKHEIMER, 1985, p. 20).
}

Assim, o objetivo no esclarecimento era extirpar os mitos e os medos em prol do domínio da natureza. No entanto, o preço pago é a sua alienação, já que, para dominar a natureza e a sua natureza, o homem se distancia dela numa relação totalitária e heterônoma. $O$ esclarecimento tem expressado a não reflexão, a positividade do pensamento e a calculabilidade matemática, o que gera a regressão ao mito do qual a humanidade jamais soube escapar. 
Os autores produziram reflexões sobre os motivos pelos quais a humanidade, contrariando as previsões iluministas, ao invés de progredir e alcançar o esclarecimento tem se inclinado cada vez mais a um processo regressivo de barbárie e heteronomia. Segundo eles, a racionalidade humana, exercida sob os parâmetros da sua instrumentalização e da lógica mercantil do modo de produção capitalista, tem sido protagonista nesse processo de manutenção da humanidade na condição de barbárie.

Nesse sentido, para Adorno e Horkheimer (1985), a separação entre teoria e prática, apesar de possuir enraizamentos na fragmentação e na divisão social do trabalho, não se situa apenas no contexto histórico da Modernidade e no advento do capitalismo; na Antiguidade já havia prenúncios do esclarecimento, pois os mitos buscavam explicações da realidade e Ulisses possuía elementos constitutivos do homem moderno.

Segundo o referencial teórico frankfurtiano, a solução para a problemática que envolve a relação entre teoria e prática não se dará por meio da reflexão sobre a prática, da ênfase nos saberes da experiência, da pesquisa ou mesmo da práxis fetichizada no contexto individual dos processos educativos. A relação tensa e contraditória entre teoria e prática, subjacente à formação de professores, não se resolverá mediante a reflexão dos sujeitos sobre seus problemas cotidianos e por meio do trabalho colaborativo entre universidade e escola.

Teoria e prática, sujeito e objeto, relacionam-se organicamente com o modo que o homem produz sua vida material, ou seja, através do trabalho e com o processo de domínio da natureza. Trata-se, portanto, de uma relação contraditória e atrelada às condições históricas do processo de domínio do homem e da natureza.

\begin{abstract}
Se o esclarecimento não acolhe dentro de si a reflexão sobre esse elemento regressivo, ele está selando seu próprio destino. Abandonando a seus inimigos a reflexão sobre o elemento destrutivo do progresso, o pensamento cegamente pragmatizado perde seu caráter superador e, por isso, também sua relação com a verdade. (ADORNO; HORKHEIMER, 1985, p. 13).
\end{abstract}

Com o objetivo de contribuir para o debate sobre os elementos constitutivos do estágio supervisionado curricular obrigatório na formação de professores de Educação Física, as reflexões desenvolvidas neste artigo apontam a necessidade de se manter a crítica imanente e a reflexão aliada à ruptura com os mecanismos que perpetuam a barbárie. De modo que, com base nas condições históricas e materiais, a humanidade possa construir uma sociedade justa e igualitária. Essas reflexões apontam ainda a necessidade de que a formação de professores não se materialize a partir da ruína progressiva da cultura teórica.

Além disso, as contribuições frankfurtianas, sobretudo de Adorno, Horkheimer e Marcuse, sinalizam a necessidade de uma maior atenção aos discursos sedutores que, de forma velada, defendem: o aligeiramento da formação docente; o recuo e a recusa da teoria; o deslocamento da formação de professores da universidade; a banalização da pesquisa e da práxis e o engodo da resolução dos problemas inerentes à relação entre 
teoria e prática. Esse cenário ideológico que impacta a formação de professores é a expressão do modo como o homem produz a sua existência, que, nessa conjuntura social, se expressa através da alienação e da divisão social do trabalho e intensifica o empobrecimento da experiência, a semiformação cultural e os mecanismos de dominação da indústria cultural.

Artigo recebido em: 31/01/2019

Aprovado para publicação em: 18/04/2019

\section{SUPERVISED INTERNSHIP AND THE CHALLENGES OF THE RELATIONSHIP BETWEEN THEORY AND PRACTICE}

ABSTRACT: The formative conceptions that theoretically subsidize the compulsory curricular supervised internship of physical education degrees have become a controversial field of debate, especially whylie refering to the discussion of the relationship between theory and practice. Based on the Critical Theory of the Frankfurt School, this article analyzes how the relation between theory and practice is discussed in the scientific productions of the stricto sensu postgraduate witch thematize stage. Immanent criticism and the principles of Theodor Adorno's negative dialectic supported the analysis of the data and made possible the understanding of contradictions existing in the proposals witch concile theory and practice and promise to solve the problems of teacher formation and of the partnership established between university and basic school, under the casing of criticality.

KEYWORDS: Teacher Formation. Compulsory Curricular Supervised Internship. Theory. Practice.

\section{EL ESTADIO SUPERVISADO Y LOS DESAFÍOS DE LA RELACIÓN ENTRE TEORÍA Y PRÁCTICA}

RESUMEN: Las concepciones formativas que subsidian teóricamente el estadio supervisado curricular obligatorio de las licenciaturas de educación física se han constituido un polémico campo de debate, especialmente cuando se remeten a la discusión de la relación entre teoría y práctica. Basándose en la Teoría Crítica de la Escuela de Frankfurt, este artículo analiza el modo como la relación entre teoría y práctica es discutida en las producciones científicas del postgrado stricto sensu que tematizan el estadio. La crítica inmanente y los principios de la dialéctica negativa de Theodor Adorno subsidiaron el análisis de los datos y posibilitaron la comprensión de las contradicciones existentes en las propuestas conciliadoras entre teoría y práctica, que prometen resolver los problemas de la formación de profesores y de la asociación entre universidad y escuela, bajo el involucro de la criticidad..

PALABRAS CLAVE: Formación de profesores. Estadio supervisado curricular obligatorio. Teoría. Práctica. 


\section{NOTAS}

1) Adorno (1995), no texto intitulado Notas marginais sobre teoria e práxis, refere-se ao termo "positividade" como algo que se assemelha a uma armadura e que, portanto, é usado analogicamente nas reflexões desta pesquisa para se referir às críticas adornianas, ao caráter totalitário e afirmativo das teorias conservadoras. $O$ uso desse termo também se respalda nas reflexões críticas de defesa do princípio de negação, do não ocultamento das contradições e da reflexão sobre seus fins. A positividade do pensamento ainda integra as elaborações críticas da Dialética Negativa (ADORNO, 2009, p. 25).

2) No texto intitulado Capitalismo tardio ou sociedade industrial, Adorno (1994) expõe suas preocupações com a adesão "engessada" de conceitos através da categoria denominada "estéril dogmatismo". O autor, a partir da crítica imanente da dialética negativa, discute os riscos e as incoerências dos processos de apropriação dos conceitos de forma dogmática.

3) Essa conciliação entre teoria e prática, a partir do pressuposto de que ambas possuem a mesma natureza constitutiva, foi encontrada em 2 teses e 6 dissertações, totalizando 57,14\% da amostra. O discurso de unir teoria e prática em prol da superação de sua dicotomia é recorrente nas produções científicas da pós-graduação stricto sensu sobre estágio supervisionado nas licenciaturas de Educação Física.

\section{REFERÊNCIA}

ADORNO, T. W. Capitalismo tardio ou sociedade industrial? In: COHN, G. Theodor Adorno. Sociologia. São Paulo: Ática, 1994. p. 62-75.

ADORNO, T. W. Notas marginais sobre teoria e práxis. In: Palavras e Sinais: modelos críticos 2. Tradução de Maria Helena Ruschel. Petrópolis: Vozes, 1995. p. 202229.

ADORNO, T. W. Dialética negativa. Tradução de Marco Antonio Casanova. Rio de Janeiro: Jorge Zahar, 2009.

ADORNO, T. W.; HORKEHEIMER, M. Dialética do esclarecimento:fragmentos filosóficos. Tradução de Guido Antônio de Almeida. Rio de Janeiro: Jorge Zahar Editor, 1985.

ALVES, M. S. Divisão social do trabalho e alienação na formação de professores de educação física da UFS: o estágio supervisionado/prática de ensino enquanto síntese dialética dos projetos em disputa. 2010. 142 f. - Dissertação (Mestrado em Educação) Faculdade de Educação, Universidade Federal de Sergipe, São Cristóvão, 2010.

AROEIRA, K. P. O Estágio como prática dialética e colaborativa: a produção de saberes por futuros professores, 2009. 253 f. Tese (Doutorado em Educação) - Faculdade de Educação - Universidade de São Paulo, São Paulo, 2009. 
BANDEIRA, L. B.; ZANOLLA, S. R. da S.; ROSA, S. V. L.

BENITES, L. C. O professor-colaborador no estágio curricular supervisionado em educação física: perfil, papel e potencialidades. 2012. 306 f. Tese (Doutorado em Ciências da Moricidade) - Instituto de Biociências de Rio Claro, Universidade Estadual Paulista, Rio Claro, 2012.

BEZERRA, B. B. Formação profissional em educação física: construção identitária de professores em formação inicial. 2012. 121 f. Dissertação (Mestrado em Educação Física) - UPE/UFPB, Recife, João Pessoa, 2012.

HORKHEIMER, M. Eclipse da Razão. Tradução de Sebastião Uchoa Leite. São Paulo: Centauro, 2002.

KRONBAUER, C. P. O curso de licenciatura em Educação Física: as contribuições dos estágios curriculares supervisionados para a formação de professores reflexivos. 2013. 140 f. Dissertação (Mestrado em Educação) - Centro de Educação, Universidade Federal de Santa Maria, Santa Maria, 2013.

MARCUSE, H. A ideologia da sociedade industrial. O homem unidimensional. 6. ed. Tradução de Giasone Rebuá. Rio de Janeiro: Zahar Editores, 1982.

MAZZOCATO, A. P. F. O professor-colaborador no estágio curricular supervisionado em Educação Física do CEFD/UFSM: constituição, concepção, orientação e contribuição. 2014. 104 f. Dissertação (Mestrado em Educação) - Universidade Federal de Santa Maria, Santa Maria, 2014.

RAMOS, G. N. S. Preparação profissional em educação física: a questão dos estágios. 2002. 136 f. Tese (Doutorado em Educação Física) - Faculdade de Educação Física, Universidade Estadual de Campinas, Campinas, 2002.

RODRIGUES, R. C. F. O estágio supervisionado no curso de educação física da UEFS: realidade e possibilidades. 2007. 103 f. Dissertação (Mestrado em Educação) - Faculdade de Educação, Universidade Federal da Bahia, Salvador, 2007.

RODRIGUES, R. C. F. Formação de professores:a prática de ensino no curso de licenciatura em Educação Física com base na concepção de formação omnilateral e da licenciatura ampliada. 2014. 174 f. Tese (Doutorado em Educação) - Faculdade de Educação, Universidade Federal da Bahia, Salvador, 2014.

SCHERER, A. O desafio da mudança na formação inicial de professores: o estágio curricular no curso de licenciatura em Educação Física. 2008. 211 f. Tese (Doutorado em Educação) - Faculdade de Educação, Universidade Federal do Rio Grande do Sul, Porto Alegre, 2008.

SOUSA, M. P. Pensando a formação inicial em educação física: entendendo o papel do estágio em uma concepção de ação docente enquanto práxis. 2012. 117 f. Dissertação (Mestrado em Educação) - Universidade Nove de Julho, São Paulo, 2012. 
TÉO, C. E. Estágio curricular supervisionado como campo de pesquisa na formação inicial do professor de educação física da UEL. 2013. 177 f. Dissertação (Mestrado em Educação) - Centro de Educação, Comunicação e Artes, Universidade Estadual de Londrina, Londrina, 2013.

ZANCAN, S. Estágio curricular supervisionado e qualidade da formação do licenciado em educação física. 2012. 116 f. Dissertação (Mestrado) - Faculdade de Educação, PUCRS, Porto Alegre, 2012.

Lílian Brandão Bandeira: Professora da área de Didáticas, Práticas e Estágio Supervisionado da Escola Superior de Educação Física e Fisioterapia de Goiás (ESEFFEGO), câmpus da Universidade Estadual de Goiás (UEG). Possui Licenciatura em Educação Física, Especialização em Metodologia do Ensino Fundamental, Mestrado e Doutorado em Educação pela Faculdade de Educação da Universidade Federal de Goiás (UFG). Tem experiência docente na Educação Básica, no Ensino Superior e com a coordenação de programas nacionais de formação de professores. Atualmente é Coordenadora Institucional do Programa de Residência Pedagógica da UEG.

Orcid: https://orcid.org/0000-0002-7636-8931

E-mail: lilian.bbandeira@smail.com

Sílvia Rosa da Silva Zanolla: Possui graduação em Psicologia e Serviço Social pela Pontifícia Universidade Católica de Goiás (PUC/GO), Mestrado em Psicologia Social pela Pontifícia Universidade Católica de São Paulo (PUC/SP); Doutorado e PósDoutorado em Psicologia Escolar e do Desenvolvimento Humano pela Universidade de São Paulo (USP). É professora Titular da Faculdade de Educação da Universidade Federal de Goiás (FE/UFG), atuando na graduação em Psicologia e na pós-graduação em Educação, com experiência em pesquisas com ênfase em psicologia social e educacional a partir da abordagem teórico crítica da Escola de Frankfurt.

E-mail: silviazanollaufg@hotmail.com

SANDRA VAlÉRIA LIMONTA ROSA: Doutora em Educação pela Universidade Federal de Goiás (UFG); mestre em Educação pela Universidade Estadual Paulista Julio de Mesquita Filho (UNESP/Marília) e licenciada em Pedagogia pela Universidade Federal de Mato Grosso do Sul (UFMS). Professora associada da Universidade Federal de 
BANDEIRA, L. B.; ZANOLLA, S. R. da S.; ROSA, S. V. L.

Goiás na Faculdade de Educação, no curso de Pedagogia (área de Fundamentos e Metodologia do Ensino de Ciências Naturais na Educação Infantil e Anos Iniciais do Ensino Fundamental) e no Programa de Pós-Graduação em Educação (Linha de Pesquisa Formação, Profissionalização Docente e Trabalho Educativo).

Orcid: https://orcid.org/0000-0002-9143-4802

E-mail:sandralimonta@gmail.com

Este periódico utiliza a licença Creative Commons Attribution 3.0, para periódicos de acesso aberto (Open Archives Iniciative - OAI). 